Case report

\title{
Caseoma: A rare echocardiographic finding of mitral annulus
}

\author{
Ekrem Şahan ${ }^{\mathrm{a}, *}$, Suzan Şahan ${ }^{\mathrm{b}}$, Murat Karamanlıoğlu ${ }^{\mathrm{a}}$, Murat Gül ${ }^{\mathrm{c}}$, Omaç Tüfekçioğlu ${ }^{\mathrm{b}}$ \\ a Atatürk Chest Disease and Thorasic Surgery Training and Research Hospital, Cardiology, Ankara, Turkey \\ b Turkiye Yuksek Ihtisas Training and Research Hospital, Cardiology, Ankara, Turkey \\ c Düzce State Hospital, Cardiology, Düzce, Turkey
}

\section{A R T I C L E I N F O}

\section{Article history:}

Received 22 February 2017

Received in revised form 13 May 2017

Accepted 15 May 2017

Available online 15 May 2017

\begin{abstract}
A B S T R A C T
Caseoma (caseous calcification of mitral annulus) is rare variant of common echocardiographic finding. Chronic caseous degeneration in the internal material of mitral annular calcification is the underlying mechanism of this condition. On the echocardiographic evaluation, the calcification is around the mass with central echolucent area, typically located at the base of the posterior leaflet. This echocardiographic finding can be mistaken for cardiac tumors, vegetations or abscesses.

(c) 2016 The Society of Cardiovascular Academy. Production and hosting by Elsevier B.V. This is an open access article under the CC BY-NC-ND license (http://creativecommons.org/licenses/by-nc-nd/4.0/).
\end{abstract}

\section{Introduction}

The calcification of mitral annulus is a common echocardiographic finding in elderly individuals. Caseoma (caseous calcification of mitral annulus) is rare variant of common echocardiographic finding of mitral annulus. Chronic caseous degeneration in the internal material of mitral annular calcification is the underlying mechanism of this condition. On the echocardiographic evaluation, the calcification is around the mass with central echolucent area, typically located at the base of the posterior leaflet. This echocardiographic finding can be mistaken for cardiac tumors, vegetations or abscesses. The differential diagnosis is important.

\section{Case report}

A 78-year-old woman with a history of hypertension, diabetes mellitus and chronic obstructive pulmonary disease was admitted for dyspnea upon minimal exertion. Her white blood cell count was normal, erythrocyte sedimentation rate and CRP levels were minimally elevated. PA chest X-ray showed massive pleural effusion at right hemithorax and elevated cardiothoracic rate. Transthoracic echocardiography (TTE) showed a large calcified mass of $27 \times 24 \mathrm{~mm}$ in the posterior mitral annulus that extended to the most basal area, the P1-P2 scallops, without causing valve stenosis (E velocity: 1,1 m/s) (Fig. 1) and with moderate mitral regurgitation (Fig. 2). Left atrial chamber and right heart chambers were dilated, left ventricular ejection fraction was $46 \%$ (modified Simpson) on echocardiographic evaluation. The patient was offered

\footnotetext{
it Peer review under responsibility of The Society of Cardiovascular Academy.

* Corresponding author at: Atatürk Chest Disease and Thorasic Surgery Research Hospital, Sanatoryum Street, 06280 Keçiören, Ankara, Turkey.

E-mail address: ekremsahan@hotmail.com (E. Şahan).
}

for transesophageal echocardiography, but patient refused invasive cardiac procedures. During the follow-up period, the patient was treated with supportive medical treatment.

\section{Discussion}

Echocardiographic series report a low prevalence of caseoma, between $0.06 \%$ and $0.07 \%$, and up to $0.6 \%$ of patients with calcification of the mitral annulus (CMA). ${ }^{1}$ In most patients, because of the asymptomatic course of caseoma, the condition is mostly underdiagnosed. Caseoma can be symptomatic, symptoms are associated with mitral valvular dysfunction, both stenosis and regurgitation. The initial diagnosis is made on echocardiography. Transthoracic echocardiography shows a spherical mass, with calcified borders and an echolucent area. ${ }^{1,2}$ A calcified mass may be shown in the cardiac silhouette of the chest X-ray. Due to the structural deformation, caseomas associated with mitral valvular dysfunction, both stenosis and regurgitation. Transesophageal echocardiography will provide more information about the internal material of CMA, also the diagnosis will be greatly aided by computed tomography (CT) and cardiac magnetic resonance imaging. ${ }^{3}$ The calcified envelope can be clearly detected by computed tomography. Cardiac magnetic resonance imaging gives the characteristics of the various sequences which will help to make differential diagnosis (especially tumors). The MRI signal is normally in T1- and T2-weighted sequences; contrast uptake is not expected at the periphery of the mass. In our hospital, transesophageal echocardiography and magnetic resonance imaging were not possible, and CT imaging was not performed because of the caution of radiation exposure. The differential diagnosis should include cardiac abscesses and tumors. The relationship between CMA and atrial fibrillation, aortosclerosis, and coronary artery disease has been studied before. ${ }^{4}$ Because the mitral annulus is close to the region of the conduction system, any extension of calcified mass would affect how this 


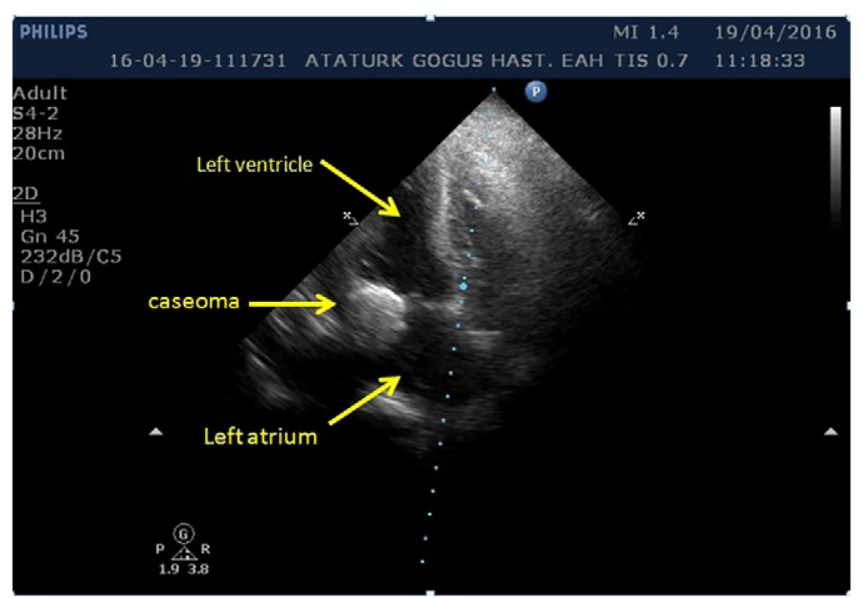

Fig. 1. Caseoma on TTE with apical four chamber view.

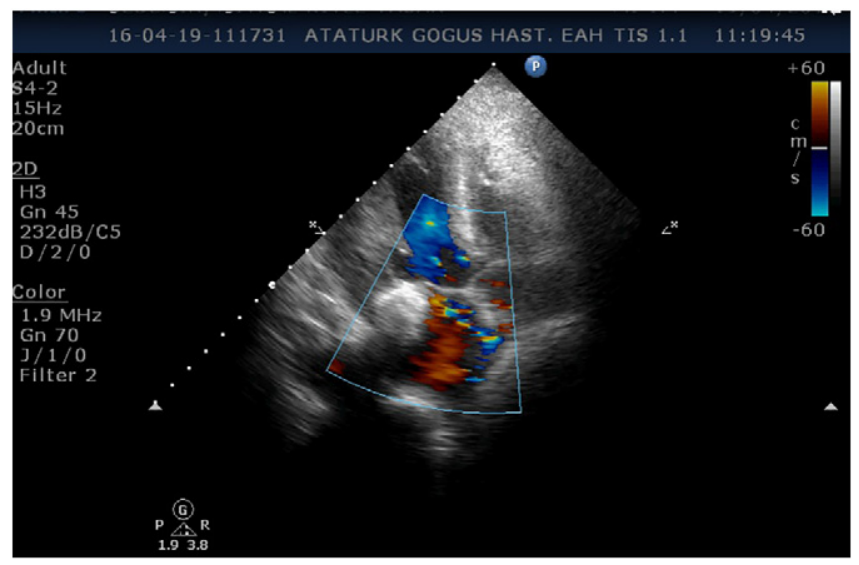

Fig. 2. Eccentrical mitral regurgitation caused by caseoma. electrical conduction function, leading to intraventricular conduction delays. Due to the asymptomatic course, only monitoring of the patient's progress is recommended in most cases. Surgery should be chosen for patients with significant valvular dysfunction or an uncertain diagnosis. ${ }^{2,3}$ In our case, due to the age of the patients and patient's chose, surgery was not performed. Because of that, no biopsy data were obtained. In conclusion, caseoma is a rare variant of calcification of the mitral annulus, but should be evaluated for the differential diagnosis with other cardiac masses to prevent unnecessary surgery.

\section{Conflict of interest}

None declared.

\section{References}

1. Deluca G, Correale M, Leva R, Del Salvatore B, Gramenzi S, Di Biase M. The incidence and clinical course of caseous calcification of the mitral annulus. J Am Soc Echocardiogr 2008;21:828-833.

2. Harpaz D, Auerbach I, Vered Z, Motro M, Tobar A, Rosenblatt S. Caseous calcification of the mitral annulus: a neglected, unrecognized diagnosis. J Am Soc Echocardiogr 2001;14:825-831.

3. Alkadhi H, Leschaka S, Pretre R, Perren A, Marincek B, Wildermuth S. Caseous calcification of mitral annulus. J Thorac Cardiovasc Surg 2005;129:1438-1440.

4. Nair CK, Thomson W, Ryschon K, Cook C, Hee TT, Sketch MH. Long-term followup of patients with echocardiographically detected mitral anular calcium and comparison with age- and sex-matched control subjects. Am J Cardiol 1989;63:465-470. 